\title{
O professor e a autoria em tempos de cibercultura: a rede da criação dos atos de currículo*
}

\author{
MARISTELA MIDLEJ SILVA DE ARAUJO VELOSO \\ Universidade Federal do Sul da Bahia, Itabuna, BA, Brasil
}

MARIA HELENA SILVEIRA BONILLA

Universidade Federal da Bahia, Salvador, BA, Brasil

\begin{abstract}
RESUMO
O trabalho tem por finalidade destacar a autoria docente na criação de atos de currículo condizentes com o contexto da cibercultura no cotidiano escolar. $\mathrm{O}$ estudo foi subsidiado pela abordagem da complexidade e pela metodologia da pesquisa-formação, articuladas com os princípios teóricos de formação de professores na cibercultura. A pesquisa foi desenvolvida em uma escola estadual e contou com a colaboração de três professoras. Foram analisadas as práticas pedagógicas dessas professoras em diferentes espaçostempos da escola, suas narrativas e os documentos de processo. $\mathrm{O}$ foco do artigo voltou-se para os processos de criação. Os resultados revelaram que a autoria/criação do professor acontece em rede, na sua temporalidade específica e relacional, reconhecendo que a formação contribuiu para que as professoras percebessem a importância de articular as dimensões pedagógica e cultural no fazer docente, além da percepção de que o professor-autor está sempre aberto aos acasos, com atenção a tudo que se passa ao redor, nos espaços analógicos e nos digitais.
\end{abstract}

PALAVRAS-CHAVE

autoria do professor; cibercultura; redes da criação.

* O artigo original foi apresentado no GT16, da Associação Nacional de Pós-Graduação e Pesquisa em Educação (ANPEd), na 37a Reunião Nacional, realizada entre os dias 4 e 8 de outubro de 2015, em Florianópolis, na Universidade Federal de Santa Catarina (UFSC). 


\title{
THE TEACHER AND AUTHORSHIP IN TIMES OF CYBERCULTURE: THE CREATION NETWORK OF THE CURRICULUM ACTS
}

\begin{abstract}
The study aims to highlight the teaching authorship in creating curriculum acts, consistent with the cyberculture context in everyday school life. The study was supported by the approach of complexity and research-formation methodology, articulated with the theoretical principles of teacher formation in cyberculture. The research was performed in a state school, with the collaboration of three teachers. We analyze their teaching practices in different school spacetimes, narratives and the process documents. The focus of the article are his creation processes. The results revealed that the authoring / creation of the teacher happens in network, in their specific and relational temporality; the formation contributed to the teachers realize the importance of articulating the educational and cultural dimensions on making teaching and the teacher-author is always open to hazards, with attention to everything that goes around in analog and digital spaces.
\end{abstract}

KEYWORDS

teacher authorship; cyberculture; creation networks.

\section{EL PROFESOR Y LA AUTORÍA EN TIEMPOS DE CIBERCULTURA: LA RED DE LA CREACIÓN DE LOS ACTOS DEL CURRÍCULO}

\section{RESUMEN}

El estudio objetiva destacar la autoría de profesores en la creación de actos del currículo en consonancia con el contexto de la cibercultura en el cotidano escolar, y se basa en el enfoque de la metodología de la complejidad y la investigación-formación, articulado con los principios teóricos de la formación del profesorado en la cibercultura. La investigación se realizó en una escuela del estado y con la colaboración de tres profesoras. Analizamos sus prácticas en diferentes espaciostiempos escolares, relatos y documentos del proceso. El enfoque del artículo son sus procesos de creación. Los resultados apuntan que la autoría/creación de profesores ocurre en red, en su temporalidad específica y relacional, que la formación ha contribuido para que los maestros diesen cuenta de la importancia de articular las dimensiones educativas y culturales en su práctica, y que el profesor-autor está siempre abierto a los acasos, con atención a todo lo que ocurre en los espacios digitales y analógicos.

PALABRAS CLAVE

autoría del professor; cibercultura; redes de la creación. 


\section{INTRODUÇÃO}

Refletir, estudar e conhecer a autoria do professor, em tempos de cibercultura, levou-nos a analisar os atos de currículo materializados nas práticas experenciadas por professores e alunos no cotidiano de uma escola pública da educação básica. Assumimos os atos de currículo com base na concepção de Macedo (2008, p. 38), que os considera como todas as atividades que os sujeitos da educação "organizam e se envolvem visando uma determinada formação, operacionalizadas via seleção, organização, formulação, implementação, institucionalização e avaliação de saberes, atividades, valores, competências". Conforme o autor, tais atividades são mediadas pelo processo de ensinar e aprender ou para a sua projeção.

De modo mais geral, o objetivo foi identificar o processo de criação/autoria do professor da educação básica, considerando o contexto atual, no qual a cibercultura vem adentrando e se constituindo, as apropriações e sentidos que os professores desenvolviam em seu fazer pedagógico, a partir da interação com as tecnologias digitais. A pesquisa foi construída sob a abordagem qualitativa, sem perder de vista que o processo de construção do conhecimento, na contemporaneidade, deve ser pautado nos princípios hologramático, da dialogicidade, da recursividade, da auto-organização, da autonomia relativa, portanto da interatividade. Por sua vez, o fundamento do pensamento complexo (Morin, 2005) leva-nos a compreender a pesquisa como uma relação entre sujeitos, na qual se constrói um conhecimento dialógico (Bakhtin, 2010c). No papel de mediadoras, em parceria com os professores, a nossa intenção foi criar/ experimentar atos de currículo no cotidiano da escola e ao mesmo tempo refletir sobre esse processo criativo, a partir dos usos das tecnologias presentes na escola e fora dela.

A pesquisa que deu origem ao presente texto foi realizada no período de 2011 a 2012, na Escola Padre Carlo Salerio, pertencente à rede pública estadual do município de Itabuna, na Bahia. A escola está situada em um bairro periférico, o São Pedro. Os alunos são de classe baixa, moradores do próprio bairro. De pequeno porte, atende aproximadamente 300 alunos ao ano, do $5^{\circ}$ ao $9^{\circ}$ ano do ensino fundamental, nos turnos matutino e vespertino, e educação de jovens e adultos (EJA) no período noturno. Atuam, na escola, 18 professores e mais 14 funcionários, entre estes, auxiliares administrativos, auxiliares de serviços gerais, merendeiras e auxiliar de portaria.

A escolha dessa escola deveu-se ao fato de ter sido uma das dez escolas baianas a receber os notebooks do Programa Um Computador por Aluno (PROUCA), ter laboratório de informática conectado à internet, alunos circulando pelos espaços da escola portando celulares, Projeto Mais Educação, ${ }^{1}$ TV Pendrive, ${ }^{2}$ uma rádio pátio, projetor educacional e professores com formação no Núcleo de Tecnologia Educa-

1 Oferece a possibilidade de educação integral a crianças, adolescentes e jovens, apoiando atividades socioeducativas em horário diferente do turno letivo escolar e promovendo ações de ampliação dos tempos e espaços educativos. Mais informações no site: <http:// www.educacao.ba.gov.br/node/319>. Na Escola Padre Carlo Salerio, há atividades no laboratório de informática e na sala de leitura envolvendo atividades com usos de filmes.

2 Televisores que foram distribuídos pela Secretaria de Educação da Bahia para todas as escolas públicas de ensino médio. 
cional/Itabuna (NTE), desenvolvendo algumas práticas pedagógicas com usos de tecnologias nos trabalhos com os alunos. Deveu-se também ao fato de que uma das autoras desse trabalho atuava no período da pesquisa no NTE e, naquele momento, estava envolvida diretamente com a formação dos professores do PROUCA no estado da Bahia, vinculada ao Grupo de Pesquisa Educação, Comunicação e Tecnologias (GEC), da Faculdade de Educação da Universidade Federal da Bahia (UFBA).

Três praticantes professoras (PP), sujeitos da pesquisa, nos acompanharam nessa investigação. $\mathrm{O}$ critério de escolha foi, principalmente, buscar aqueles professores que estivessem dando indícios de modificação nas práticas pedagógicas mais tradicionais ou outros que apenas estivessem abertos para a criação de novas práticas e experimentações e demonstrassem interesse pela pesquisa.

A PP1 é graduada em letras, especialista em metodologia da língua portuguesa (2007). Atua há mais de vinte anos na docência, em escolas da rede particular e estadual. Iniciou sua prática docente atuando no ensino de língua portuguesa e há mais de cinco anos leciona língua inglesa e artes, além de coordenar as atividades da rádio pátio. A PP2 é graduada em letras (2000), com habilitação em língua inglesa, especialista em língua portuguesa, literatura e produção de texto. Possui mais de vinte anos de docência, lecionando em escolas particulares e das redes municipal e estadual, nas disciplinas literatura e língua portuguesa. A PP3 é licenciada em geografia e em história, especialista no ensino de geografia (2000). Atua na docência há mais de vinte e um anos, nas redes municipal e estadual, lecionando as disciplinas história, geografia e artes.

No presente artigo não analisaremos os atos de currículo criados pelas PP, mas os seus processos de criação. Para a efetivação do objetivo proposto, inicialmente será desenvolvido o desenho metodológico da pesquisa. Em seguida, em dois tópicos complementares, apresentaremos o que estamos entendemos por rede da criação e o processo de autoria do professor no contexto da cibercultura, buscando situar o leitor sobre os conceitos básicos que subsidiam a compreensão do objeto de estudo. Posteriormente serão apontadas as noções subsunçoras, ${ }^{3}$ que são constituintes do processo criativo do professor. $\mathrm{O}$ último tópico refere-se às considerações finais.

\section{DESENHO METODOLÓGICO}

Para investigar os atos de currículo realizados cotidianamente pelos sujeitos, autores e atores das práticas pedagógicas, colocamo-nos diante do desafio de

3 Considerando a base teórica adotada na pesquisa, falar de categorias e/ou estruturas de análise prévias para sistematizar os conhecimentos de algo que está em constante estado de atualização, efêmero, como o cotidiano, limita a análise. Em contrapartida, seguindo Macedo (2006), que, norteado pelos fundamentos da etnopesquisa, entende que na leitura interpretativa das informações construídas no percurso da investigação, em várias oportunidades, aparecem significados e acontecimentos, recorrências, índices representativos de fatos observados, contradições e ambiguidades, e em certo momento aparece a necessidade de reagrupar as informações, no que ele denomina de noções subsunçoras, ou seja, "[...] as categorias analíticas —, que irão abrigar sistematicamente os subconjuntos das informações, dando-lhes feição mais organizada em termos de um corpus analítico escrito de forma clara" (Macedo, 2006, p. 138). 
mergulhar no cotidiano escolar, de acordo com Alves (2008) e Ferraço (2008), buscando compreender suas complexidades em meio às redes de fazeressaberes ${ }^{4}$ que são tecidas por esses praticantes em suas narrativas, usos, negociações, articulações.

Não havia uma pretensão de "ver" ou apreender a totalidade, mas considerar e conhecer os atos de currículo do cotidiano escolar em sua pluralidade, diversidade e singularidades. A nossa intenção era ver/ouvir/sentir o que essa vida ordinária/ comum (Certeau, 2009) desse espaçotempo tinha para contar, buscando uma compreensão da realidade complexa que envolvia as ações concretas de autoria dos professores, aprendendo com eles, os parceiros da pesquisa. Nosso interesse foi pensar os indícios da criação/autoria do professor no contexto da cibercultura a partir da criação cotidiana de atos de currículo, nos seus documentos de processo e narrativas. Dessa forma, optamos pela pesquisa-formação, com base etnográfica, em consonância com as proposições de Macedo $(2006,2010)$ e Josso (2010), entendendo-a como uma metodologia em que existe o compromisso dos pesquisadores, seja numa prática de mudança individual ou coletiva, incluindo diferentes atividades, "seja do ponto de vista da disciplina de pertença dos pesquisadores, seja do ponto de vista dos campos de operação, seja, enfim do ponto de vista dos objetivos de transformação (Josso, 2010, p. 101). Segundo Macedo (2006), tal abordagem tem características da pesquisa-ação, mas, ao ser voltada para a educação, tem suas especificidades metodológicas, as quais implicam uma proposição, uma ação formativa.

Em nosso caso, constituímos um grupo com as praticantes professoras do cotidiano da escola envolvidas na investigação, portanto a autoria foi compartilhada por todos. No papel de pesquisadoras ativas e envolvidas com o processo formativo e de aprendizagens, fomos, com os professores, formando-os e nos formando. Santos (2005) afirma que a pesquisa não é um espaço para olhar o fenômeno de fora, ao contrário, como diz Freitas (2002, p. 153), “[...] é um espaço de formação e autoformação, um espaço de implicação, onde o risco, a incerteza, a desordem serão contemplados sem perder o rigor de fazer ciência".

Com esse pensamento, buscou-se deixar claro para as praticantes professoras da escola, desde o começo do processo, que não havia a intenção de transferir conhecimentos, conteúdos, nem a formação era pensada na perspectiva do formar como uma "[...] ação pela qual um sujeito criador dá forma, estilo ou alma a um corpo indeciso e acomodado. [Visto que] não há docência sem discência, as duas se explicam e seus sujeitos, apesar das diferenças que os conotam, não se reduzem a condição de objeto um do outro" (Freire, 2011, p. 25). O autor ainda destaca que, na prática, "[...] embora diferentes entre si, quem forma se forma e re-forma ao formar e quem é formado forma-se e forma ao ser formado" (Freire, 2011, p. 25). Portanto, como o autor expressa, quem ensina aprende ao ensinar, e quem aprende ensina ao aprender. Essa era uma fala constante em nossos encontros.

4 Estética de escrita que aprendemos com Nilda Alves (2008). Para ela, "a junção dos termos e sua inversão, em alguns casos, quanto ao modo como são 'normalmente' enunciados, nos pareceu, há algum tempo, a forma de mostrar os limites para as pesquisas nos/dos/com os cotidianos, do modo dicotomizado criado pela ciência moderna para analisar a sociedade" (Alves, 2008, p. 11). 
Em contrapartida, com a consciência de que “[...] ninguém forma ninguém e que pertence a cada um transformar em formação os conhecimentos que adquire ou as relações que estabelece" (Nóvoa, 2004, p. 23), além do fato de que na pesquisa-formação, como ressalta Macedo (2000), há uma importância do diálogo, que se configura em uma relação de interatividade e proximidade entre pesquisador e pesquisado e também com o meio no qual a produção e a significação dos enunciados são fontes inesgotáveis de informações ao pesquisador em sua busca da compreensão do fenômeno estudado, tivemos prudência e cuidado com a concepção e organização dos dispositivos de pesquisa. Para compreender o movimento de criação das professoras no cotidiano da escola, além da observação dos atos do currículo materializados nas suas práticas pedagógicas, organizamos os seguintes dispositivos de pesquisa: os encontros de formação, as nossas conversas, os diários de pesquisa e os documentos de processo.

Na perspectiva da pesquisa-formação, além de acompanhar os professores nas atividades de sala de aula, foram organizados alguns encontros de formação. O objetivo dos momentos formativos não era somente contribuir para que os professores utilizassem o laboratório de informática ou os notebooks. Para além desses usos, as experimentações e as discussões tinham como propósito abrir uma possibilidade de vivência coletiva para sentir os limites que impossibilitavam essa inserção em suas práticas. Os encontros com caráter investigativo não propiciavam apenas a coleta de dados, mas objetivavam, principalmente, a construção dos dados e a participação dos envolvidos, considerados sujeitos históricos culturais, o que implica compreendê-los como possuidores "[...] de uma voz reveladora da capacidade de construir um conhecimento sobre sua realidade que o torna coparticipante do processo de pesquisa" (Freitas, 2003, p. 39). Os dados foram construídos nas atividades a cada encontro presencial com os professores e nos relatos e discussões nos ambientes virtuais (blog da escola, blog dos professores, no e-Proinfo, no Moodle, no Facebook), analisados ao longo da investigação.

Dentro da corrente das pesquisas nos/dos/com os cotidianos, eram realizadas, a todo momento, rodas de conversas, conforme sinalizado por Berino et al. (2009), buscando apoio na experiência que Eduardo Coutinho desenvolve em seus filmes. Para esse cineasta, o que se faz no cotidiano é trocar experiências, o que justifica a preferência do termo "conversa" no lugar de "entrevista", visto que "a entrevista, depoimento, pressupõe uma formalização que destrói o clima de diálogo espontâneo que é importante [...]" (Coutinho, 1997, p. 166). Fugindo da lógica das habituais entrevistas, as conversas foram tomadas no sentido dialógico (Bakhtin, 2010a), visando, mais que ao simples trabalho de pergunta e resposta, à construção e à reconstrução de sentidos, um exercício constante de "escuta sensível".

Para os registros da imersão no campo da pesquisa, com finalidades diferentes, foram utilizados dois tipos de diários, o jornal de pesquisa (JP) e o diário de campo, sendo o primeiro público e o segundo privado. Para Borba (2010), citado por Barbosa e Hess (2010), o JP é mais que um diário íntimo, pois nele você se expressa, socializa os ocorridos, permite uma troca que pode criar relações fortes entre os sujeitos em formação. O nosso JP online foi criado na interface blog. ${ }^{5} \mathrm{~A}$ ideia não

5 Endereço: <http://jornaldepesquisaucabahia.blogspot.com.br/>. 
era somente expor os caminhos, mas principalmente refletir sobre as vivências que se conectavam para criar a rede de relações que geravam a pesquisa e que nos constituía como autoras do trabalho, além de potencializar a abertura para a cocriação de nossos parceiros nesse processo, no caso os formadores do curso do PROUCA/ $\mathrm{BA}$ e os professores da escola. $\mathrm{O}$ diário de campo/itinerância foi utilizado como um bloco de apontamentos. Nele, anotamos nossos sentimentos, pensamentos, meditações, retenções de teorias, de conversas, construções que davam sentido ao nosso percurso de investigação. Nessa direção, Macedo afirma que, ao construir o seu diário de campo, o etnopesquisador reafirma sua autoria, pois, na elaboração e na construção do sujeito e do objeto, "passa por um trabalho de elaboração daquilo que nos constitui tanto em nível imaginário quanto real. Portanto, ao narrar despojada e minuciosamente seu vivido de pesquisador, o sujeito se constitui também" (Macedo, 2006, p. 134).

Para a compreensão da autoria dos professores, foram também utilizados os documentos do processo de criação como dispositivos de análise. Tais documentos foram entendidos pela ótica de Salles (2008a, 2008b, 2010) e de Macedo (2006). Salles (2008a, p. 28) afirma que esses documentos ajudam a compreender, "[...] no próprio movimento da criação, os procedimentos da produção, e, assim, entender o processo que presidiu o desenvolvimento da obra”. Para Macedo (2006), o documento como fonte de análise é qualquer expressão escrita dos sujeitos da pesquisa - redações, projetos, comunicações informais. Assim, no caso desta pesquisa, todos os registros deixados pelos professores foram importantes, pois apontavam informações significativas na ação criadora, visto que a obra - no caso, o ato de currículo, materializado na prática pedagógica — não é fruto de uma única ideia localizada em momentos iniciais do processo, mas disseminada em todo o percurso. Há criação em projetos, nos cadernos de anotações, diários, nas anotações em livros, rascunhos, portfólios, planos de aula, nos computadores etc.

É preciso deixar claro que, como salienta Salles (2008b), não é possível analisar os documentos de forma isolada, pois a criação se dá nas relações dos acontecimentos de percurso, portanto o conceito de rede abrange características marcantes no processo de criação, tais como: simultaneidade de ações, ausência de hierarquia, não linearidade e intenso estabelecimento de nexos. Assim, durante a análise dos documentos, fomos destacando alguns aspectos mais recorrentes/exacerbados das práticas dos sujeitos participantes do estudo que apontassem o desenvolvimento do pensamento em criação.

Limites e possibilidades de uma metodologia de pesquisa no/do/com o cotidiano das escolas são apontados por Esteban (2003), comentados e ampliados por Ferraço (2008). Um deles é que essa abordagem de pesquisa parece sempre nos colocar diante de riscos, porque as ideias do pesquisador não são reflexos do real, mas tradução dele, e toda tradução é passível de erro. Esteban chama atenção para o fato de que a pesquisa no cotidiano conduz todos os sujeitos nela envolvidos por um terreno movediço, opaco, híbrido, levando-os a percorrer um caminho que vai sendo constituindo como possível. Em contrapartida, defende a autora que os riscos não significam a inexistência de tentativas teórico-metodológicas de condução rigorosa e responsável do processo e de compromisso com os resultados 
apresentados, mesmo que entendidos como parciais e provisórios e que o rigor não signifique neutralidade e mensuração. A autora afirma que essa opacidade demanda um rigor flexível. Evidencia que essa pesquisa não pode ser completamente exposta, pois na sua realização ficam guardados alguns mistérios, ao colocar em ação tipos de conhecimento indizíveis, que não podem ser mensuráveis, como um cheiro, um olhar ou até mesmo uma intuição.

Esteban e Ferraço consideram que para pesquisar o cotidiano da escola, mais que adaptar metodologias conhecidas, é preciso desenvolver metodologias de pesquisa específicas, para além das explicações causais-lineares presentes nos modelos predominantes nas pesquisas, pois o que se pretende na investigação é, além de explicar os fenômenos emergentes, aprofundar a compreensão e a interpretação sobre a realidade numa perspectiva dialógica, interativa. Para Ferraço (2008), essa perspectiva de pesquisa tem uma potência no que se refere às possibilidades que se tecem nas redes cotidianas, mas impõe desafios acerca de como conduzi-la perante a complexidade manifestada no cotidiano escolar, pois, como alerta Esteban (2003, p. 201), a dinâmica existente no cotidiano é marcada pela incerteza, e em alguns momentos pode nem ser possível dar visibilidade aos laços que conectam o fragmento à teia das relações que o conformam.

Ainda a referida autora indica que um mesmo processo coletivo pode possibilitar diferentes procedimentos individuais, marcados pelas singularidades das experiências, ao mesmo tempo em que faz com que procedimentos individuais semelhantes configurem processos coletivos diversos. Segundo ela, como consequência, são muitas as relações possíveis e não há trajetos predefinidos, lineares, cujos pontos de origem sejam fixos e os pontos de chegada previsíveis. Outra dificuldade posta por Esteban para a criação e análise dos dados, nas pesquisas que elegem a escola como campo, é a própria teoria do caos em realização, onde tudo acontece ao mesmo tempo.

Ferraço afirma que, de modo geral, os caminhos encontrados têm decorrido da própria epistemologia que o cotidiano impõe. Mas, apesar das diversas alternativas propostas pelos pesquisadores cotidianistas, todos partilham de algumas ideias comuns no tocante a uma dada condição de atuar nas pesquisas, entre elas a necessidade de rompimento com determinadas amarras do modelo cartesiano de pesquisa, tomando como referência a epistemologia da complexidade (Morin, 2005). Ao citar Nilda Alves (2001), Ferraço (2008) aponta um caminho, quando a autora afirma que é necessário discutir e criar conhecimentos sobre as múltiplas fontes de pesquisa que surgem nos cotidianos escolares, articulados com as narrativas, originadas das conversas, dos depoimentos ou escritos pessoais, sempre presentes e necessárias nos processos de tessituras e partilha das redes de saberesfazeres dos sujeitos praticantes.

\section{A CRIAÇÃO COMO REDE E/OU A REDE DA CRIAÇÃO: A CONSTITUIÇÃO DA AUTORIA}

A concepção de autoria no contexto da cibercultura que sustentou a proposta de compreensão do processo de criação do professor no cotidiano da escola 
toma como base o arcabouço teórico de Bakhtin (2010a, 2010b, 2010c), no tocante ao autor-criador e ao princípio dialógico constituinte do ato da criação, e, mais especificamente, os estudos de Cecília Salles (2008a, 2008b, 2010) referentes ao percurso da criação do artista. Em ambos, respeitando suas especificidades, há uma concepção de criação/autoria numa dimensão social, dialógica, interativa, em rede.

Entendemos, a partir de Salles (2008b, p. 35-36), que a criação é muito menos fruto de uma inspiração e mais resultado advindo de trabalho, portanto de um processo que "abarca o raciocínio responsável pela introdução de ideias novas, que abarca, por sua vez, essa perspectiva de transformação". Desse modo, segundo a autora, pode-se falar que há criação em diferentes processos de produção, em qualquer área, diferindo apenas a tendência do processo, a natureza dos elementos conectados e os recursos utilizados para as associações de ideias.

A criação é aqui entendida como processo em rede, ou seja, “[...] um percurso de interconexões instáveis, gerando nós de interação, cuja variabilidade obedece a alguns princípios direcionadores" (Salles, 2010, p. 17). Essas interconexões, para Salles, envolvem a relação do artista (no nosso caso, dos professores) com seu espaço e seu tempo, articulando questões relativas à memória, à percepção, à escolha de recursos criativos, assim como as diversas maneiras como se organizam as tramas do pensamento em criação.

Ao incorporar o conceito de rede, numa perspectiva social, interacionista, Salles (2008b, p. 152) sinaliza que "[...] a autoria se estabelece nas relações, ou seja, nas interações que sustentam a rede, que vai se constituindo ao longo do processo de criação", o que permite dizer que a autoria é sempre coletiva, apesar de respeitar as singularidades do autor que assina a obra/prática. No entanto, conforme afirma Bakhtin (2010b, p. 310), na autoria “[...] sempre há algo individual, único e singular, e nisso reside todo o seu sentido, sua intenção em prol da qual ele [referindo-se ao texto] foi criado". O autor não concebe a autoria a partir da unicidade do sujeito, um gênio criador, iluminado, dono do seu próprio dizer. Para Bakhtin, a autoria não é exclusivamente originalidade. Para ele, "[...] o objeto do discurso do falante, seja esse objeto qual for, não se torna pela primeira vez objeto do discurso em um dado enunciado, e um dado falante não é o primeiro a falar sobre ele" (Bakhtin, 2010c, p. 299-300). Todo discurso se entrelaça com outros discursos existentes, uma vez que não há um discurso único, pois realmente "[...] repetimos todo enunciado, além do seu objeto, sempre (no sentido amplo da palavra) de uma forma ou de outra aos enunciados do outro que o antecederam" (Bakhtin, 2010c, p. 300).

Portanto, é nesse movimento interlocutivo, nas ressonâncias dialógicas, na interação que a autoria é constituída. O autor-criador, ao enunciar, já responde aos outros-ditos da cadeia da comunicação, ao mesmo tempo em que abre para possíveis respostas ao seu enunciado, para outros dizeres. Como afirma Bakhtin (2010b, p. 326), "todo o dado se transforma em criado", e, como nos mostra Salles (2008b, p.19), "[...] a criação artística é marcada por sua dinamicidade que nos põe, portanto, em contato com um ambiente que se caracteriza pela flexibilidade, não fixidez, mobilidade e plasticidade". 
De forma análoga, pode-se afirmar que o pensamento criativo do professor manifesta-se em vários momentos, tais como: uma conversa com um aluno ou com um colega, uma leitura, um objeto encontrado por acaso, uma pesquisa na internet ou até mesmo um olhar diferente para a prática que foi desenvolvida. Cada um deles pode gerar uma gama de possibilidades, que podem ser continuadas ou não. Como constata Salles (2008b, p. 35), as interações são, muitas vezes, responsáveis pelo surgimento de novos caminhos, que podem dar origem a uma rede de possibilidades de desenvolvimento de uma nova prática pedagógica, pois "os elementos selecionados já existiam, a inovação está no modo como são colocados juntos, ou seja, na maneira como são transformados".

Considerando a posição dos autores citados, o desenvolvimento da autoria, de práticas mais inovadoras, vai depender do nível de abertura da rede estabelecida no ambiente da criação. Johnson (2011, p. 47) considera as redes abertas como "redes líquidas". Enquanto nas redes sólidas/fechadas, “[...] os padrões têm estabilidade, mas são incapazes de mudança, uma rede líquida cria ambiente mais promissor para o sistema explorar o possível adjacente, ${ }^{6}$ [onde] novas configurações podem emergir por meio de conexões aleatórias". Para tornar nossa mente mais inovadora, temos de inseri-la em ambientes/redes de ideias e pessoas que exploram o possível adjacente, visto que "[...] certos ambientes acentuam a capacidade natural do cérebro de estabelecer elos de associação" (Johnson, 2011, p. 43).

Salles (2008b) alerta que é impossível definir, com precisão, o local e o tempo da criação, pois suas práticas estão em constante estado de mutabilidade, os momentos da criação estão espalhados por todo o processo. Esse movimento desencadeia a ideia de ação em permanente continuidade, e, em sala de aula, ainda que a prática planejada seja materializada em determinado momento, fica a sensação de que se cumpriu apenas uma parte dos desejos do professor. Como afirma Salles (2008b), a criação como rede está sempre em um estado de inacabamento, nunca conseguimos apreendê-la como um ponto-final.

A posição de Salles (2008b), inspirada em Morin (2011), nos aponta um caminho para observar o professor inserido na efervescência cultural, deparando-se com objetos sociotécnicos, pessoas de diferentes culturas, envolvido em uma diversidade de trocas, lidando com tensões entre ideias, polêmicas entre opiniões, concepções e práticas. Dessa forma, podemos dizer que o professor, em seu percurso criador, dialoga com outras culturas, "[...] no seu aspecto social, alimenta-se do outro, portanto imerso e sobredeterminado pela sua cultura (que por seu estado de efervescência possibilita o encontro de brechas para a manifestação de desvios inovadores)" (Salles, 2008b, p. 40). É no lançar mão dos artefatos culturais, próprios de seu tempo, para a sua aprendizagem e de seus alunos, que os professores assumem apropriações, atribuindo-lhes significado e sentido.

Portanto, pode-se compreender que a autoria se dá por meio de um processo em rede, mesmo em atos aparentemente individuais, nas relações com o outro e nas

6 Ideias ou objetos que servem como possibilidades de novas criações, próximas ao que desejamos criar. 
relações com os objetos sociotécnicos. Na criação, os sujeitos imersos na cultura, mesmo tendo acesso a igual material cultural, podem chegar aos mesmos ou a diferentes resultados, dependendo do sentido dado por cada um deles e das interações advindas do seu entorno.

\section{CIBERCULTURA: A CULTURA DE NOSSO TEMPO}

Vivenciamos, atualmente, um período de aceleradas transformações sociais. As sociedades evoluem e se modificam ao longo do tempo, por influência de muitos fatores, a exemplo do conhecimento produzido e das tecnologias que lhe são próprias. Em cada momento histórico, as relações existentes entre tecnologia, conhecimento e autoria, adquirem características específicas. Mas esses fatores não apenas influenciam as transformações sociais; eles são também influenciados e constituídos pela cultura e pela configuração social. Sociedade/cultura e tecnologia/produção de conhecimento contribuem na construção do curso da história, por meio de relações muito próximas, inter-relacionadas e complexas. É em razão disso que, para compreender como se constitui a autoria do professor no momento atual, necessitamos levar em consideração a cultura contemporânea.

É fato que as tecnologias digitais afetam a todos os processos na atualidade. Surgiram novos modos de produzir, transmitir, receber e conservar a informação, e a cultura é influenciada por esse mundo dinâmico, virtual, em rápida mutação. Além da pluralidade das informações disponíveis, estas são de fácil acesso, produzidas e divulgadas de forma horizontalizada, com maior facilidade. As linguagens e os signos que circulam pelos ambientes virtuais permitem materializar as diferentes formas de expressão, aproximando as pessoas, por mais distantes geograficamente que se encontrem. Os textos transformam-se em hipertextos interativos, conectados, que são revertidos, fragmentados, reatualizados e disponibilizados em novo contexto, por uma nova comunidade, com diferente autoria.

Ramal (2002) afirma que o hipertexto digital é a melhor metáfora e das maiores experiências para ilustrar a articulação entre obra/textos/leitor/autor. Embora essa interação não se limite apenas às redes digitais, é onde se pode colocá-la em maior evidência, por proporcionar uma experiência tecnológico-cultural que mais potencializa "[...] a intertextualidade, a polifonia e o dialogismo. Permanentemente disponível para ser de novo tecido a qualquer momento por leitores de qualquer parte da imensa rede digital, o hipertexto já é, desde a sua concepção, uma reunião de vozes" (Ramal, 2002, p. 123).

Os interagentes (Primo, 2007) tecem esse hipertexto digital porque habitam o ciberespaço, um local de relação social, de criação de conhecimento, um espaço do saber, um conjunto de técnicas (materiais e intelectuais). Nesse movimento, desenvolvem práticas, atitudes, modos de pensamento e de valores próprios desse meio, a chamada cibercultura (Léevy, 1999). Para Lemos (2003), a cibercultura é um conjunto tecnocultural que emerge no século XX, impulsionado pela sociabilidade pós-moderna na nova relação entre tecnologias digitais (ciberespaço, simulação, tempo real, processos de virtualização etc.) e o surgimento das redes telemáticas mundiais. A partir de então, vive-se a cultura do acesso e da ubiquidade 
(Santaella, 2007), de tal forma que o aspecto fundamental para se compreender a complexidade da cultura contemporânea encontra-se no caldeirão de misturas e hibridações que a caracterizam, visto que "[...] todas as formas de cultura, desde a cultura oral até a cibercultura hoje coexistem, convivem e sincronizam-se na constituição de uma trama cultural hipercomplexa e híbrida" (Santaella, 2007, p. 128).

Essa formação sociocultural rompe com a dinâmica informacional baseada na relação "um para todos", própria do modelo broadcasting, potencializando a troca "todos para todos", na qual todos podem ser autores e coautores das mensagens, quase em tempo real, independentemente de distribuição geográfica e da diferença de horário. É o meio propício para que cada indivíduo possa ser, ao mesmo tempo, emissor e receptor de informações e sentidos. A liberação da palavra constitui o primeiro princípio da cibercultura, do qual emerge um segundo princípio, a conexão e a conversação mundial (Lemos e Lévy, 2010, p. 25), ou a inteligência coletiva (Lévy, 1999). A conectividade generalizada (Lemos, 2003,2005,2010) é o segundo princípio e significa que "tudo está em rede", o que começa com a transformação do computador pessoal em computador coletivo, com o surgimento da internet e, deste, para o computador coletivo móvel (Lemos, 2003), com a era da ubiquidade e da computação pervasiva desde o início do século XXI, com a explosão dos celulares e das redes $W i-F i$. Essa evolução técnica põe em contato direto homens e homens, homens e máquinas, assim como máquinas e máquinas, que passam a trocar informações, formando redes sociotécnicas, permitindo que o sujeito, mesmo estando só, não fique isolado, ou seja, "[...] tudo comunica e tudo está em rede: pessoas, máquinas, objetos, cidades. É a era do que alguns chamam de 'Internet das coisas', onde objetos os mais diversos passam a se comunicar conectando-se à Internet" (Lemos e Lévy, 2010, p. 46).

Em decorrência, emerge o terceiro princípio, a reconfiguração social, cultural e política, com as novas formas de produção e circulação da opinião pública, agora abertas, multimidiáticas e interativas (Lemos e Lévy, 2010, p. 26). Lemos (2010) afirma que se trata, na realidade, de reconfigurar práticas, modalidades mediáticas, espaços, agregando novas técnicas, sem a substituição de seus antecessores.

Para Lemos (2005), esses três princípios estão na base da ciber-cultura-remix, ${ }^{7}$ uma consequência do potencial das tecnologias digitais para recombinar/remixar. Portanto, na escola, com acesso ao ciberespaço, professores e alunos têm a possibilidade de ser mais que meros consumidores dos recursos prontos, vindos de outros contextos, passando a construir conteúdos próprios, ao mesmo tempo sem se distanciarem da "[...] produção histórica da humanidade, mas sim com ela estabelecendo um diálogo franco e aberto, favorecido pelas redes, articulando de forma intensa o saber local com o saber planetário, remixando conhecimentos, culturas, no tempo e no espaço" (Pretto, 2011, p. 113).

7 O termo remix foi originado das práticas de remixes das músicas produzidas em torno dos anos de 1960 e início de 1970 em Nova York, tendo suas raízes na música da Jamaica. Hoje, o remix foi estendido para outras áreas da cultura. 
Diversos artefatos, não só os oriundos da escola (documentos dos professores, livros, anotações), também os de diferentes culturas - televisiva, literária, artística, digital - são acessados. Como os professores vivem em busca de ideias, que podem ser encontradas por eles ou pelos alunos, tudo olham, recolhem o que possa ser de interesse, acolhem e rejeitam, fazem montagens, organizam, de forma que "ideias se associam, formas alternativas proliferam e pesquisas integram a obra em construção"(Salles, 2008b, p. 40). Ou seja, em tudo há possibilidades interativas, potencialidades para a criação. $O$ professor alimenta-se de tudo que o envolve e a partir daí faz suas escolhas. E a web impulsiona o "navegar" em busca de mais informações, mais do que na cultura dominada por livros e pelos meios de comunicação de massa. A web nos oferece uma infinidade de informações surpreendentes, além de possibilitar percorrer trilhas de associações improvisadas, com mais facilidade e velocidade que as mídias impressas (Johnson, 2011). As informações publicadas em livros, revistas e jornais limitam-se aos espaços físicos próprios, reduzindo a possibilidade de encontros com os acasos.

Consideramos que o acaso é um elemento importante à criação do professor, pois, como nos chama atenção Cole (2006), vivemos imersos em um mundo pleno de estímulos visuais, imagéticos, sonoros e intelectuais. Alguns deles nos passam despercebidos, outros impulsionam nossa imaginação. Tal qual os imprevistos, esses acasos no cotidiano da escola contribuem para que, ao término de uma aula, o professor já comece a planejar a seguinte. Cada prática planejada e executada, ou ainda não posta em ação, é apenas uma das tantas versões possíveis, que podem ser atualizadas a qualquer momento. O que nos move é o desejo de que algum dia encontremos uma prática que satisfaça plenamente a nós e a nossos alunos.

\section{A REDE DA CRIAÇÃO DO PROFESSOR NO CONTEXTO DA CIBERCULTURA}

Ao analisar o processo de autoria do professor, nos remetemos a Salles (2008b), quando afirma que é impossível estabelecer uma separação entre o artista e seu projeto poético e que, portanto, o processo de criação é um espaço de constituição da subjetividade. De modo análogo, podemos constatar que prática docente e professor "não só estão imbricados de modo vital, como estão em mobilidade. São redes em permanente constituição” (Salles, 2008b, p. 152).

Ao acompanharmos as professoras implicadas em seus processos criativos e formativos no cotidiano da escola, encontramos elementos constituintes de tais percursos. A ideia foi, ao analisar os processos criativos das praticantes professoras, fazer uma inter-relação entre os aspectos mais gerais da criação e aqueles inerentes às singularidades, à autoria de cada praticante professora.

Analisando os rastros da criação nos atos de currículos praticados e nos documentos de processo, chegamos às seguintes noções subsunçoras, que são constituintes do processo criativo dos professores participantes da pesquisa: os espaçostempos da criação: os escritórios pessoais e o escritório coletivo; os móbeis internos e externos; as redes líquidas de colaboração: saberesfazeres, pessoas e ideias. 


\section{ESPAÇOSTEMPOS DA CRIAÇÃO}

A primeira noção subsunçora, espaçostempos da criação: os escritórios pessoais e o escritório coletivo, diz respeito a onde e quando acontece o movimento da criação, assim como os objetos que são inseridos nesse processo. As professoras apontam os lugares e o tempo, do planejamento ao desenvolvimento, de suas práticas, além dos objetos que são utilizados por elas. Dessa forma, situamos o sujeito cultural em seus espaçostempos de criação.

Tomamos emprestado o termo "escritório" de Salles (2008b, p. 51), que o utiliza em referência a qualquer local de trabalho, independentemente do nome que receba: ateliê, estúdio, sala, entre outros. No caso do professor, pode ser qualquer espaço - lugar praticado (Certeau, 2009) — onde ele pensa/planeja/organiza suas aulas, um lugar mais individualizado, como um compartimento de sua casa, ou ambientes coletivos da escola, como a sala de professores, ou até mesmo a sala de aula, onde decisões são tomadas o tempo inteiro. Esses espaços não são só "guardiões da coleta cultural" (Salles, 2008a), mas também espaços da ação desse profissional, onde a criação se efetiva. $\mathrm{O}$ escritório compõe-se como lugar de múltiplas ações: de estudos, de reflexões, de planejamento, de experimentações e de elaborações e correções de atividades, de armazenamento de materiais.

Os espaços praticados pelos sujeitos nos mostram, pelos materiais neles presentes (dados, objetos, informações, livros, revistas), rastros do processo criativo. Porém, espaço e tempo não podem ser analisados separadamente, visto que “o espaço da criação abriga trabalho físico e mental [...]” (Salles, 2008b, p. 59), ao longo do qual as intenções, as metodologias, os objetos, os saberes tomam forma. Por esse motivo, a autora ressalta que, "discutir o tempo da criação é, antes de mais nada, tratá-lo no plural” (Salles, 2008b, p. 59), pois o processo criativo implica um movimento permanente, sempre em estado de construção. Assim, o escritório está impregnado das marcas das ações dos professores, ao mesmo tempo integrado ao seu movimento criador e cultural.

Visitamos as residências das três PP com o intuito de identificar os artefatos culturais que faziam parte de seus respectivos escritórios e a sua organização. Ressaltamos que foi dispensada certa atenção a um dos documentos de processo das praticantes professoras, o caderno de anotação. Nos referidos cadernos há vários elementos que marcam o processo criativo de cada professora. Mas, como não podemos trazer todos eles, destacamos um, por intermédio da fala de PP2, ao afirmar que usa tal recurso para fazer rabiscos:

[...] são rabiscos de qualquer jeito, de qualquer forma. [...] tem algumas anotações, tudo que acontece; coisa da jornada, texto trabalhado... [...] Aí, vem a atuação dos alunos; quem veio e quem não veio; quem fez e quem deixou de fazer... As coisas interessantes que eles dizem eu rabisco [...] Aí, eu releio ele todo, todas as anotações que eu fiz. Como foi elaborado? Quais foram os passos? Quem participou? Por que não participou? E eu vou anotando... o que deu certo, ótimo! O que não deu, eu vou ver o que foi que faltou para que aquele trabalho desse certo. (PP2) 
Percebe-se, na fala da professora, o entendimento dos registros como documentos comprobatórios do trabalho desenvolvido, uma espécie de memória do seu fazer, das relações estabelecidas com os alunos e, também, da possibilidade de avaliação da prática para um possível refazer.

A organização dos escritórios pessoais, enquanto espaço de trabalho, de modo singular, nos revelaram os hábitos, as escolhas temáticas e metodologias, entre tantos outros aspectos do processo de criação de cada uma delas. Também percebemos algumas semelhanças na organização dos escritórios das três professoras praticantes. Observa-se que hoje o escritório é um espaço limitado, onde a tecnologia ocupa um lugar de destaque, tendo em vista que os materiais impressos já estão se deslocando para outros espaços mais distanciados daquele em que o professor circula com maior frequência. As visitas a seus baús e a suas estantes são cada vez mais esporádicas. Constatamos que o processo da criação das professoras, em tempos de cibercultura, está vinculado à internet, embora esse artefato cultural seja usado por elas apenas como espaço de pesquisa. Diante das lacunas encontradas em seu percurso formativo, além das condições inadequadas das escolas, ainda não conseguem incorporar o computador e a internet de forma plena em seu trabalho pedagógico, como um artefato de criação, restringindo as ações que vão além do consumo de informações.

Além dos escritórios individuais, os professores contam com o escritório coletivo, a sala de professores. Por falta de espaço na escola, parte da sala de professores é transformada em ateliê para os professores de artes. Lá, a PP3 guardava e manuseava o material utilizado em suas criações. No referido escritório, mesmo que o professor não esteja fazendo alguma atividade sistematizada, dita como "pedagógica", ele pode estar em um momento de reflexão e/ou dialogando com seus colegas. Nesse ínterim, nessas conversas (consigo mesmo ou com o outro), "nossa mente pode se deparar muitas vezes com alguma velha conexão que não notávamos havia muito, proporcionando aquela deliciosa sensação de serendipidade íntima: por que não pensei nisso antes?” (Johnson, 2011, p. 92). São nesses momentos que algumas boas ideias vão emergindo, outras vão sendo ampliadas ou até mesmo descartadas da prática docente.

Era na sala de professores que encontrávamos, com certa frequência, professores aprendendo juntos, partilhando seus saberes, buscando sanar dúvidas. É no contato com os pares que os saberes vão sendo construídos, por isso é preciso "conceber a escola como um ambiente educativo, onde trabalhar e formar não sejam atividades distintas" (Nóvoa, 2002, p. 29). Uma das reclamações de uso da sala destinada aos professores é a interrupção frequente de alunos, pais de alunos, gestores e funcionários da escola, além de conversas entre os próprios professores que não são de interesse de alguns dos que se encontram ali, naquele momento.

As dificuldades, em parte, são em consequência do tempo curto que lhes é destinado, fora de sala de aula, para a realização de outras atividades do trabalho pedagógico, como planejamento, correção de atividades, estudos, entre tantas outras. Fomos habituados a levar para casa as atividades que deveriam ser realizadas em horário de trabalho e a cumpri-las de forma isolada, de tal forma que essa prática foi naturalizada, tornou-se cultural. A perspectiva do trabalho numa dimensão 
interacional e em rede ainda está em processo de incorporação na vida profissional dos professores.

Essas questões adquirem maior ou menor grau de relevância, dependendo do professor e de suas singularidades. Salles (2008b, p. 58) constata que os "escritórios" coletivos, "mesmo nas atividades que preveem essa convivência, sempre oferecem algum tipo de conflito e resistência, ao mesmo tempo em que são vistos como extremamente motivadores". Enquanto uns fazem dele escritórios pessoais, com usos intensos, outros não conseguem realizar ali quase nenhum tipo de trabalho.

\section{OS MÓBEIS INTERNOS E EXTERNOS}

A segunda noção subsunçora, os móbeis internos e externos, emergiu a partir das narrativas das professoras em relação ao que as mobilizam para a renovação e a criação autoral de suas práticas. De acordo com as explicações de Charlot (2000), a mobilização pressupõe a ideia de movimento. $\mathrm{O}$ autor prefere o termo "mobilização" a "motivação", pois mobilizar implica envolver-se ("de dentro"), enquanto motivação tem origem no estímulo provocado por algo ou alguém ("de fora"). Para o autor, esses conceitos convergem, podendo-se dizer que alguém se mobiliza para alcançar um objetivo que lhe motiva e que é motivado por algo que pode mobilizá-lo. A mobilização está mais direcionada para a dinâmica do movimento, da atividade.

Charlot sustenta que o conceito de mobilização, além da noção de movimento, remete à ideia de recursos e de móbil. Portanto, "mobilizar é "pôr recursos em movimento" e engajar-se em uma atividade originada por móbiles, porque existem boas razões para fazê-lo" (Charlot, 2000, p. 55). O móbil, que o autor distingue da meta, é o desejo que permite a satisfação e que desencadeou a atividade.

Portanto, consideradas as concepções de Charlot, para o sujeito tornar-se autor é necessário uma mobilização, além da produção de sentidos em torno do que precisa ser construído. Ao sentir-se mobilizado, o professor busca a mudança em suas práticas. Podemos afirmar, com base na ótica do pensamento complexo, numa visão sistêmica, que não podemos dissociar os móbeis internos dos externos. Há um processo de interdependência entre eles.

Os móbeis que se destacaram durante a pesquisa foram o contexto da cibercultura (a sociedade da informação) e o perfil dos alunos. A infinidade de informações disponíveis na internet a cada minuto e a imersão dos alunos no ciberespaço confrontam o papel e o conhecimento do professor na sala de aula, o que ele faz e o que ele deve fazer, uma vez que, em outros tempos, ele era visto como única fonte de informação sobre os mais diversos temas. As professoras reconhecem a necessidade de uma mudança de postura diante dos alunos, assumindo-se como o professor que não sabe tudo e que está disposto a também aprender com eles, o que leva a uma maior interação entre eles e maior participação dos alunos nas atividades na sala de aula. Percebe-se que esse envolvimento dos alunos as mobiliza.

As PP participantes da nossa pesquisa vêm percebendo estarem diante de novas exigências, o que tem thes mobilizado para a atualização e renovaçao das práticas. O desejo de atrair a atenção dos alunos, de mobilizá-los para aprender, 
tem desafiado as praticantes professoras a buscar metodologias mais condizentes com as formas de ensinar e aprender próprias do contexto da cibercultura.

$\mathrm{O}$ reconhecimento/valorização pelo trabalho realizado também emergiu como móbil. As narrativas das PP nos fizeram constatar que o reconhecimento e a valorização do seu trabalho aumentam a autoestima, mobilizando-as, colocando-lhes em movimento para a realização do trabalho pedagógico. As professoras precisam do olhar externo, que as ajude a enxergar o que vêm realizando, a refletir sobre as metodologias que vão sendo incorporadas no fazer docente, para, então, tomar consciência das próprias criações. No caso da PP3, com o incentivo e a resposta favorável dos alunos ao seu trabalho, realiza o desejo de produzir e publicar um texto, a partir de um conteúdo curricular, para ser incorporado ao material oferecido aos alunos.

A formação para uso da tecnologia foi, ainda, um móbil que se destacou. A falta de familiarização dos professores com as tecnologias é um dos fatores que dificulta a inserção desses artefatos culturais no cotidiano da escola. No momento em que se inicia um trabalho de formação mais pontual, os professores começam a descobrir outras possibilidades para o fazer docente e se mobilizam para incorporar as tecnologias nas práticas pedagógicas.

Concordando com Nóvoa (2011), pudemos constatar que os programas de formação contínua, pautado em modelos estruturantes, têm se revelado inúteis, pois a maioria deles não consegue provocar mudanças nas práticas instituídas. Quando se investe "na construção de redes de trabalho colectivo que sejam suporte de práticas de formação baseadas na partilha e no diálogo profissional” (Nóvoa, 2011, p. 23), dando visibilidade, em rede, aos projetos da escola e aos projetos da pessoa e do profissional professor, aproximando-se dos desejos desses praticantes e da realidade escolar, dos problemas sentidos por eles, desperta-se no professor um sentimento de pertença e de identidade profissional. Essa rede de colaboração na formação contribui para que os professores se apropriem dos processos de mudança e sintam-se mobilizados para a realização de práticas concretas de intervenção. Consideramos que "em formação é preciso entender que a emoção coloca o sujeito em movimento e o impulsiona para a ação" (Macedo, 2010, p. 129).

\section{REDES LÍQUIDAS DE COLABORAÇÃO}

A terceira noção subsunçora encontrada na pesquisa foram as redes líquidas de colaboração: saberesfazeres, pessoas e ideias. Conforme Johnson (2011), nos ambientes densamente povoados e abertos a novas ideias, diferentes formas de colaboração são possíveis. Conseguimos vislumbrar essa constatação na escola pesquisada, pois sentimos que, no momento em que a escola passou a ser frequentada por pessoas que não faziam parte do seu quadro de funcionários (formadores da instituição de ensino superior (IES) e do NTE e alunos de graduação de outra IES) e que passaram, de certa forma, a fazer parte do cotidiano da escola, formou-se uma rede líquida (Johnson, 2011) de colaboração — seja presencialmente ou por meio de ambientes virtuais, um maior número de ideias começou a circular, potencializando novas criações. 
Percebemos, na escola, não só a abertura para o acolhimento de colaboradores externos - sejam eles pessoas que adentravam no espaço físico da escola ou nas redes virtuais onde a escola estava inserida, sejam ainda os objetos sociotécnicos mas também a abertura para a colaboração entre os professores e os funcionários administrativos, a coordenadora pedagógica e os alunos, em busca da inovação no trabalho pedagógico. Percebemos que com as sugestões desses colaboradores foi possível incorporar novas atividades aos trabalhos das PP.

Para mediar o processo de ensino e aprendizagem entre os espaços híbridos (o presencial e o virtual), o professor necessita de saberes específicos, diferentes daqueles necessários para desenvolver as práticas cotidianas tradicionais. Pesquisas (Pereira, 2008; Ferreira, 2011) revelam um conjunto de saberes essenciais para a atuação no contexto da cibercultura ou, como designado por eles, na educação online. Destacam-se a mediação pedagógica, a interatividade, a colaboração e os saberes tecnológicos. As praticantes professoras da pesquisa sinalizam que tais saberes ainda estão em processo de construção, entre elas, e que as dificuldades para inserir as tecnologias digitais na sala de aula eram derivadas da necessidade de construção de novos saberes.

No entanto, à medida que se sentiam amparadas pela rede de colaboração, que trocavam ideias com outros professores, que percebiam o retorno dos alunos, que se mobilizavam para o desenvolvimento de novas práticas, iam construindo esses novos saberes. Ou seja, os saberes do professor são mobilizados e empregados nas interações diárias da escola, "saberes esses que dela provêm, de uma maneira ou de outra, e servem para resolver os problemas dos professores em exercício, dando sentido às situações de trabalho que lhes são próprias" (Tardif, 2002, p. 58).

Todo percurso criativo, conforme Salles (2011, p. 94), quando observado pela ótica de sua continuidade, "coloca os gestos criadores em uma cadeia de relações, formando uma rede de operações estreitamente ligadas". Nas conversas com as professoras, além da observação de suas práticas, conseguimos perceber os procedimentos e os recursos utilizados por elas e como o pensamento ia materializando-se no fazer docente. A PP2 nos conta como é que seu pensamento criativo vai desenrolando-se no decorrer das ações de sala de aula:

Eu preparo, claro, eu tenho meus passos, eu sigo o programa, o planejamento! [...] Mas eu não sou muito presa, não, pela questão da abertura que eu dou ao aluno de encaminhar a minha aula... A "nossa” aula, porque não é minha só! [...] se for o conteúdo do livro, eu digo o assunto e onde é que nós vamos estudar o conteúdo. Então, a partir daí, eu já vou para a questão do levantamento prévio, da provocação. [...] E, daí, a aula flui. (PP2)

A narrativa da professora mostra que a sua criação, apesar de ter uma proposta inicial, não segue um planejamento fechado, com regras preestabelecidas, com a aula sendo elaborada no movimento gerado pela turma, a partir dos conhecimentos prévios dos alunos, e processo semelhante ocorre com as demais professoras participantes da pesquisa. 
O que fica implícito nas narrativas das professoras é que, apesar de reconhecerem a importância do planejamento e de terem consciência dos conteúdos obrigatórios em cada série (tomando como referência as orientações curriculares ofertadas pela Secretaria de Educação do Estado), é na ação que elas refletem sobre as demandas de formação de seus alunos e lançam mão dos conteúdos formais e/ou informais, criando seus etnométodos e táticas, "descobrindo saídas, inventando e experimentando novas soluções e adaptando-se constantemente”(Woods, 1999).

Ao final de uma aula emergem, ao mesmo tempo, satisfação em torno de questões que foram consideradas bem desenvolvidas e insatisfação pelo fato de outras questões não terem sido exploradas como gostariam que fosse; no entanto, já começam a vislumbrar outras formas de trabalhar com essas questões, em outros momentos, ou com outras turmas. Ou seja, é um processo sempre em desenvolvimento, em que, em sua incompletude, alguns elementos (recursos, metodologias etc.) se mantêm, e a partir da inter-relação com outros emergem novas práticas, potencializando outras criações.

Dessa forma, podemos observar que uma ação, em determinada turma, se completa com um evento que aconteceu em outra; que um problema, uma dúvida ou uma dificuldade do professor, pode ser resolvido por meio de uma leitura, de uma conversa com o coordenador pedagógico ou com seus pares, ou até mesmo com os próprios alunos. Na perspectiva da crítica de percurso, como afirma Salles (2008b, p. 22), essa visão do processo de criação nos coloca no campo relacional, não podendo isolar seus componentes, e, sim, contextualizá-los, ativando as relações que o mantêm como sistema complexo. Esse movimento dinâmico, conforme nos mostra a autora, organiza-se em intenções, desejos e acasos que direcionam para construções de obras que, ao mesmo tempo em que têm um rumo, caminham para um estado de incertezas e imprecisões. E nesse percurso que, segundo Salles (2008b), se constroem novas obras.

Em virtude da flexibilidade do percurso criador diante das incertezas e da não garantia de melhores práticas, há um permanente movimento de idas e vindas, adequações, avaliações, reaproveitamentos, rejeições. Todas as três professoras deixaram claro, em seus depoimentos, suas angústias quando em suas aulas não consegue atingir os objetivos. Tais acontecimentos deixam desejos recalcados, a espera de outras oportunidades para retomá-los. As ações da criação demonstram que lidamos com um tempo da criação docente em uma perspectiva não linear.

\section{CONSIDERAÇÕES FINAIS}

$\mathrm{Na}$ análise processual da autoria do profissional professor, não foi suficiente conhecer a prática ou apresentar os materiais que foram utilizados pelos professores e que estão presentes nos documentos com a intenção apenas de identificá-los ou listá-los. O essencial foi estabelecer relação entre eles, e deles com a prática materializada em sala de aula. Tampouco importou descrever o processo criador ou falar do professor ou do produto final, mas tentar reconstruir seus passos, com o intuito de descobrir o pensamento que suporta a construção da prática materializada na sala de aula. Os documentos de processo de criação ajudaram a esclarecer 
as formas de diálogos do professor com os materiais/objetos de aprendizagem e os diferentes pensamentos que se davam no movimento da produção, bem como os diferentes momentos em que ocorrem os processos de criação.

Observamos, nesse processo da pesquisa-formação, que a autoria/criação dos professores aconteceu em rede, na sua temporalidade específica e relacional. Essa rede foi constituída de diversos elementos, nós que se entrelaçavam no movimento da criação; entre eles, destacamos: móbeis internos e externos, os recursos, as relações culturais, a memória, os acasos, a formação colaborativa, os saberes docentes. A partir da percepção dessa rede, concluímos que, nesse contexto, o professor-autor não nasce pronto e que é na relação com o outro e com a cultura que novas criações emergem. A emergência das ideias depende da dinâmica organizacional e institucional dos cenários educacionais, da mobilização afetiva e cognitiva em ambientes propícios e motivantes que possibilitam a reflexão e os meios para que os sujeitos interajam entre si e com diferentes elementos culturais.

Lançar mão de determinados recursos "passa a ser mais um meio condutor de diálogos externos, que trazem para dentro do processo outras vozes, muitas vezes chamadas de influências" (Salles, 2008b, p. 44). Esses diálogos são positivos para o desenvolvimento da autoria, visto que essa diversidade de referências constitui a trama das interações de que é feita a história de criação de cada professor. As professoras participantes da pesquisa, atentas a objetos novos e interessantes para a aprendizagem de seus alunos, estão sempre abertas aos acasos, com atenção voltada a tudo que se passa em redor, seja nos espaços analógicos, seja nos digitais.

É preciso uma tomada de consciência de que o professor pode e deve ser autor da própria prática, que a criação está no sujeito, basta que as condições lhes sejam dadas. O desafio está no incentivo a uma nova formação docente, na qual professor e alunos compartilhem de um processo conjunto para aprender de forma dialógica. Diante dos nossos estudos e nas vivências possibilitadas por esta pesquisa, constatamos que é preciso formação em contexto, em serviço, políticas de formação de professores menos diretivas e mais focadas na formação para a autonomia, que potencialize no professor o reconhecimento de si mesmo, como pessoa, como profissional, como agente social da educação. Este trabalho revela que a autoria docente não se descola da pessoa do professor; a autoria do professor não se ensina, se pratica coletiva e colaborativamente, no cotidiano da escola, em um eterno estado de inacabamento.

\section{REFERÊNCIAS}

Alves, N. Decifrando o pergaminho: os cotidianos das escolas nas lógicas das redes cotidianas. In: Oliveira, I. B.; Alves, N. (Orgs.). Pesquisa nos/dos/com os cotidianos: sobre redes de saberes. Petrópolis: DP et alii, 2001. p. 13-38.

. Decifrando o pergaminho: os cotidianos das escolas nas lógicas das redes cotidianas. In: Oliveira, I. B.; Alves, N. (Orgs.). Pesquisa nos/dos/com os cotidianos: sobre redes de saberes. Petrópolis: DP et alii, 2008. p. 15-38. 
Barbosa, J. G.; Hess, R. O diário de pesquisa: o estudante universitário e seu processo formativo. Brasília: Liber Livro, 2010.

Bakhtin, M. Apontamentos. In: . Estética da criação verbal. 5. ed. São Paulo: WMF Martins Fontes, 2010a. p. 261-306.

. O problema do texto na linguística, na filologia e em outras ciências humanas. In: ___ Estética da criação verbal. 5. ed. São Paulo: WMF Martins Fontes, 2010b. p. 367-392.

. Gêneros do discurso. In: . Estética da criação verbal. 5. ed. São Paulo: WMF Martins Fontes, 2010c. p. 307-335.

Berino, A. P. et al. Sobre conversas. In: Macêdo, E.; Macêdo, R. S.; Amorim, A. C. (Orgs.). Discurso, texto, narrativas nas pesquisas em currículo. Campinas: UNICAMP, 2009. p. 100-109.

Certeau, M. A invenção do cotidiano: 1. Artes de fazer. 16. ed. Petropólis: Vozes, 2009. Charlot, B. Da relação com o saber: elementos para uma teoria. Tradução de Bruno Magne. Porto Alegre: Artmed, 2000.

Cole, A. D. O processo de criação artística e a constituição da cultura. Revista Mackenzie de Educação, Arte e História da Cultura, São Paulo: Editora Mackenzie, v. 5, n. 5/6, p. 92-101, 2006. Disponível em: <http://editorarevistas.mackenzie.br/index.php/reahc/ article/view/505>. Acesso em: 15 out. 2012.

Coutinho, E. O cinema documentário e a escuta sensível da auteridade. In: AnTonacci, M. A.; Perelmutter, D. (Orgs.). Projeto História - ética e história oral. São Paulo: PUC, abr. 1997. v. 15, p. 165-191.

Esteban, M.T. Dilemas para uma pesquisadora com o cotidiano. In: Garcia, R. (Org.). Método: pesquisa com o cotidiano. DP\&A, 2003. p. 199-212.

Ferraço, C. E. A pesquisa em educação no/do/com o cotidiano das escolas. In: Oliveira, I. B.; Alves, N. (Orgs.). Pesquisa nos/dos/com os cotidianos: sobre redes de saberes. Petropólis: DP et alii, 2008. p. 23-34.

Ferreira, M. C. A. Saberes pedagógicos/comunicacionais, pesquisa/formação: reflexões sobre as experiências formativas das professoras online. 2011. Tese (Doutorado em Educação) — Universidade Federal do Rio Grande do Norte, Natal, 2011.

Freire, P. Pedagogia da autonomia: saberes necessários à prática educativa. São Paulo: Paz e Terra, 2011.

Freitas, M.T.A.A abordagem sócio-histórica como orientadora da pesquisa qualitativa. Cadernos de Pesquisa, São Paulo: Fundação Carlos Chagas; Campinas: Autores Associados, n. 116, p. 21-39, jul. 2002.

A perspectiva sócio-histórica: uma visão humana da construção do conhecimento. In: Freitas, M. T. A.; Jobim, S.; Kramer, S. (Orgs.). Ciências humanas e pesquisa: leitura de Mikhail Bakhtin. São Paulo: Cortez, 2003. p. 26-38.

Johnson, S. De onde vêm as boas ideias. Rio de Janeiro: Zahar, 2011.

Josso, M. C. Caminhar para si. Tradução de Albino Pozzer. Porto Alegre: EDIPUCRS, 2010. 
Lemos, A. Cibercultura: alguns pontos para compreender a nossa época. In: Lemos, A.; Cunha, P. Olhares sobre a cibercultura. Porto Alegre: Sulina, 2003. p. 11-23.

. Ciber-Cultura-Remix. In: Seminário "Sentidos e Processos", 2005, São Paulo.Anais... São Paulo: Itaú Cultural, ago. 2005. Disponível em: <http://www.facom. ufba.br/ciberpesquisa/andrelemos/remix.pdf> Acesso em: 24 abr. 2010.

Os sentidos da tecnologia: cibercultura e ciberdemocracia. In: Lemos, A.; LÉvY, P. O futuro da internet: em direção a uma ciberdemocracia planetária. São Paulo: Paulus, 2010. p. 21-31.

Lemos, A.; LÉvy, P. O futuro da internet: em direção a uma ciberdemocracia planetária. São Paulo: Paulus, 2010.

LÉvy, P. Cibercultura. Tradução de Carlos Irineu da Costa. São Paulo: Editora 34, 1999. MACEDo, R. S. A etonopesquisa crítica e multireferencial nas ciências humanas e na educação. Salvador: EDUFBA, 2000.

. Etnopesquisa crítica, etnopesquisa-formação. Brasília: Liber Livro, 2006.

. Currículo: campo, conceito e pesquisa. 2. ed. Petropólis: Vozes, 2008.

. Compreender/mediar a formação: o fundante da educação. Brasília: Liber Livro, 2010.

Morin, E. Introdução ao pensamento complexo. Porto Alegre: Sulina, 2005.

. $O$ método 4: as ideias, habitat, vida, costumes, organização. 5. ed. Porto Alegre:

Sulina, 2011.

NóvoA, A. Formação de professores e trabalho pedagógico. Lisboa: Educa, 2002.

. Prefácio. In: Josso, M. C. Experiências de vida e formação. São Paulo: Cortez, 2004. p. 11-17.

. O regresso dos professores. Pinhais: Melo, 2011.

Pereira, S. A. C. Saberes docentes em ambientes virtuais de aprendizagem. 2008. Dissertação (Mestrado em Educação) — Faculdade de Educação, Universidade Federal da Bahia, Salvador, 2008.

Pretto, N. L. O desafio de educar na era digital: educações. Revista Portuguesa de Educação, Braga: CIED, Universidade do Minho, v. 24, n. 1, p. 95-118, 2011. Disponível em: <http://revistas.rcaap.pt/rpe/article/view/3042>. Acesso em: 10 ago. 2013.

PRIMo, A. Interação mediada por computador: comunicação, cibercultura, cognição. Porto Alegre: Sulina, 2007.

Ramal, A.C. Educação na cibercultura: hipertextualidade, leitura, escrita e aprendizagem. Porto Alegre: Artmed, 2002.

Salles, C. A. Crítica genética: fundamentos dos estudos genéticos sobre o processo de criação artística. São Paulo: EDUC, 2008a.

. Redes da criação: construção da obra de arte. 2. ed. São Paulo: Horizonte, 2008b. . Arquivos de criação: arte e curadoria. Vinhedo: Editora Horizonte, 2010. . Gesto inacabado: processo de criação artística. 5. ed. São Paulo: Intermeios, 2011.

Santaella, L. Linguagens líquidas na era da mobilidade. São Paulo: Paulus, 2007. 
TARdif, M. Saberes docentes e formação profissional. 2. ed. Petrópolis: Vozes, 2002.

Woods, P. Aspectos sociais da criatividade do professor. In: NóvoA, A. (Org.). Profissão professor. Porto: Porto Editora, 1999. p. 125-153.

\section{SOBRE AS AUTORAS}

Maristela Midlej Silva de Araujo Veloso é doutora em educação pela Universidade Federal da Bahia (UFBA). Professora da Universidade Federal do Sul da Bahia (UFSB).

E-mail: marimidlej@gmail.com

Maria Helena Silveira Bonilla é doutora em educação pela Universidade Federal da Bahia (UFBA). Professora da mesma instituição.

E-mail:bonilla@ufba.br

Recebido em 18 de março de 2016 Aprovado em 18 de julho de 2017 